\title{
Analysis of the immune-related transcriptome of a lophotrochozoan model, the marine annelid Platynereis dumerilii Boran Altincicek and Andreas Vilcinskas*
}

\author{
Address: Institute of Phytopathology and Applied Zoology, Interdisciplinary Research Center, Justus-Liebig-University of Giessen, Heinrich-Buff- \\ Ring 26-32, D-35392 Giessen, Germany \\ Email: Boran Altincicek - Boran.Altincicek@agrar.uni-giessen.de; Andreas Vilcinskas* - Andreas.Vilcinskas@agrar.uni-giessen.de \\ * Corresponding author
}

Published: 6 July 2007

Frontiers in Zoology 2007, 4:18 doi:10.1186/1742-9994-4-18

This article is available from: http://www.frontiersinzoology.com/content/4/I/l8

(c) 2007 Altincicek and Vilcinskas; licensee BioMed Central Ltd.

This is an Open Access article distributed under the terms of the Creative Commons Attribution License (http://creativecommons.org/licenses/by/2.0), which permits unrestricted use, distribution, and reproduction in any medium, provided the original work is properly cited.
Received: 25 December 2006

Accepted: 6 July 2007

\begin{abstract}
Background: The marine annelid Platynereis dumerilii (Polychaeta, Nereididae) has been recognized as a slow-evolving lophotrochozoan that attracts increasing attention as a valuable model for evolutionary and developmental research. Here, we analyzed its immune-related transcriptome. For targeted identification of immune-induced genes we injected bacterial lipopolysaccharide, a commonly used elicitor of innate immune responses, and applied the suppression subtractive hybridization technique that selectively amplifies cDNAs of differentially expressed genes.
\end{abstract}

Results: Sequence analysis of 288 cDNAs revealed induced expression of numerous genes whose potential homologues from other animals mediate recognition of infection (e.g. complement receptor CD35), signaling (e.g. myc and SOCS), or act as effector molecules like ferritins and the bactericidal permeability-increasing protein. Interestingly, phylogenetic analyses implicate that immune-related genes identified in $P$. dumerilii are more related to counterparts from Deuterostomia than are those from Ecdysozoa, similarly as recently described for opsin and intronrich genes.

Conclusion: Obtained results may allow for a better understanding of Platynereis immunity and support the view that $P$. dumerilii represents a suitable model for analyzing immune responses of Lophotrochozoa.

\section{Background}

Comparative immunology has become an integrative discipline in zoology and has gained wide acceptance in biological sciences [1]. Research on molecular aspects of innate immunity was mainly performed on Ecdysozoa (Drosophila [2] and Caenorhabditis [3]) or Deuterostomia (fish and murine models), whereas information about immune responses from Lophotrochozoa is rather fragmentary and needs further elucidation. Identification of immune-related genes from lophotrochozoan species was performed by differential display RT-PCR in the leech Theromyzon tessulatum (Annelida, Hirudinea) [4] and by subtractive suppression hybridization, the same method as used in this study, in the oysters Crassostrea virginica and C. gigas (Mollusca, Bivalvia) [5] and the snail Biomphalaria glabrata (Mollusca, Gastropoda) [6,7]. Here, we used the marine polychaete Platynereis dumerilii for targeted screening of the immune-related genes because this annelid has been emerged as an ideal model organism for evolutionary analyses of a slow-evolving Bilateria $[8,9]$. 
Since genomic data become available from an increasing number of invertebrates such as the sea urchin Strongylocentrotus purpuratus [10], comparative immunology attracted renewed attention. But screening for immunerelated genes in genomic or EST databases has one major disadvantage. It allows only the identification of genes that share sequence similarities with known immunerelated proteins from other organisms. Here, we used an experimental approach for targeted screening of immunerelated genes in $P$. dumerlii that allows selective amplification of genes with enhanced expression rates in response to septic injury. For this purpose, we injected crude bacterial lipopolysaccharide (LPS), a potent and widely used elicitor of innate immune responses, into the coelom of adult Platynereis, isolated their RNA 8 hours post challenge, and analyzed immune-related transcripts by a subtractive suppression hybridization approach. This PCRbased method selectively amplifies cDNAs of differentially expressed genes and simultaneously suppresses amplification of common cDNAs. This technique has been proven as a suitable tool for identification of immune-related genes in a variety of animals including the apterygote insect Thermobia domestica [11], the mosquito Anopheles gambiae [12], the tsetse fly Glossina morsitans [13], the lepidopterans Galleria mellonella and Manduca sexta [14,15], the oysters C. virginica and C. gigas [5], the snail B. glabrata [6,7], and the zebrafish Danio rerio [16]. Here, we describe the identification of immunerelated genes from $P$. dumerlii which may provide novel insights into polychaete innate immunity.

\section{Results and Discussion Subtracted CDNA library of immune challenged $P$. dumerilii}

A subtracted cDNA library enriched in immune-inducible genes was constructed using purified RNA from eight adult $P$. dumerilii injected with bacterial LPS and eight untreated animals. To induce strong and broad immune responses we injected a commercially available purified LPS preparation that is known to contain impurities like nucleic acids, proteins, and peptidoglycans and that is commonly used as elicitor in vertebrate and invertebrate research. In order to confirm that the subtraction process has been performed efficiently, we analyzed the abundance of transcripts of the house-keeping genes $18 \mathrm{~S}$ rRNA and $\alpha$-tubulin and for two genes, the bactericidal permeability-increasing protein (BPI) and suppressor of cytokine signaling (SOCS). The latter ones were found to be induced in response to immune challenge in Platynereis. Quantitative real-time PCR analyses revealed that transcripts of $18 \mathrm{~S}$ rRNA and $\alpha$-tubulin were reduced 2 to 3 fold, whereas transcripts of BPI and SOCS were enriched for 1.3 and 5.1 fold, respectively (Fig. 1). This is in agreement with values from the protocols of the manufacturer and indicates successful subtraction of the cDNA library.
A total of 288 clones from this library were randomly picked and subjected to colony PCR. Plasmids of $140 \mathrm{col}-$ onies that were positively screened in blot hybridization indicating immune-induced expression of corresponding genes were isolated and sequenced. Obtained sequences were deposited at EMBL-European Bioinformatics Institute, compared to databases of the National Center for Biotechnology Information using BLASTX program, and summarized in table 1. InterProScan at the EMBL-European Bioinformatics Institute was used for an integrated search in PROSITE, Pfam, and PRINTS databases to predict conserved motifs, signal sequences, and transmembrane regions.

Here, we describe the identification of $P$. dumerilii proteins that are potentially involved in recognition of infection, immune-related signaling, and effector mechanisms based on sequence similarities with known proteins from other organisms.

\section{Recognition of infection}

The complement system is an important component of innate immunity in vertebrates [17]. Because no complement genes were found in Drosophila and Caenorhabditis it has previously been suggested that the complement system is solely established in deuterostomes [18]. However, recently $\mathrm{C} 3$ was identified in the horseshoe crab (Arthropoda) and in corals (Cnidaria) implicating a much more ancient origin [18]. In this study we identified Platynereis transcripts encoding a protein that shares sequence similarities with human complement receptor type $1(\mathrm{C} 3 \mathrm{~b} /$ $\mathrm{C} 4 \mathrm{~b}$ receptor, CD35 antigen) (Fig. 2). In addition, we found cDNAs encoding a protein sharing highest sequence similarities with mouse C-C chemokine receptor type 1 (Macrophage inflammatory protein 1-alpha receptor, CD191 antigen) which is a G-protein coupled receptor for C-C type chemokines [19]. However, the similarities of obtained sequences to the potential counterparts are to short and to prevalent in similar receptors to construct a useful phylogenetic analysis; therefore, the given assignments should be taken with care.

\section{Signaling}

The engagement of immune-related signaling pathways result in the massive production of cytokines and effector molecules that are necessary for pathogen elimination but that can also cause self-damage. Consequently, the regulation of exuberant immune responses is of great importance for the organism. In agreement, we found numerous genes in $P$. dumerilii that encode homologues known as negative regulators of immune responses. We identified the induced expression of a protein with highest sequence similarity to SOCS. SOCS proteins are negative feedback loop regulators of the evolutionary well-conserved JAK/ STAT (Janus Kinase/Signal Transduction and Activator of 
Table I: cDNAs from the subtracted $P$. dumerilii library

\begin{tabular}{|c|c|c|c|c|c|}
\hline Cluster & EMBL accession \# & Highest BlastX match & $E$ value & PFAM/InterPro & PEPD EST clone ID \\
\hline \multicolumn{6}{|c|}{ Defense proteins } \\
\hline & AM697673 & PI7213: Bactericidal permeability-increasing protein (Homo sapiens) & 0.036 & $\mathrm{BPI} 2$ & \\
\hline & AM697674 & P42577: Soma ferritin (Lymnaea stagnalis) & $6 e-69$ & Ferritin & AAAY-59-09-D \\
\hline & AM697675 & P08267: Ferritin heavy chain (Gallus gallus) & $2 e-33$ & Ferritin & AAAY-70-04-A \\
\hline & AM697676 & P80060: Protease inhibitors (Locusta migratoria) & 0.0017 & & AAAC-30-10-H \\
\hline & $\overline{\mathrm{AM} 697677}$ & Q5MGQ0: Defense protein I (Lonomia obliqua) & $5 e-05$ & Reeler & \\
\hline & $\overline{\mathrm{AM} 697678}$ & P9|778: Alpha-amylase (Pecten maximus) & $2 e-48$ & Alpha-amylase & \\
\hline \multicolumn{6}{|c|}{ Signal transduction } \\
\hline & AM697681 & PI7927: Complement receptor type I (CD35, Homo sapiens) & $2 e-06$ & Sushi & \\
\hline & $\overline{\mathrm{AM} 697682}$ & P51675: C-C chemokine receptor type I (CDI9I, Mus musculus) & $2 e-07$ & $7 \mathrm{tm} \_\mathrm{I}$ & \\
\hline & $\overline{\mathrm{AM} 697683}$ & Q7TPQ9: Arrestin domain-containing protein 3 (Mus musculus) & $2 e-22$ & Arrestin_C & \\
\hline & AM697684 & Q9PW70: Suppressor of cytokine signaling (Gallus gallus) & $3 e-12$ & $\mathrm{SH} 2$ & \\
\hline & $\overline{\mathrm{AM} 697685}$ & Q80T79: CUB and sushi domain-containing protein 3 (Mus musculus) & 0.3 & & \\
\hline & $\overline{\mathrm{AM} 697687}$ & P49709: Myc protein (Carassius auratus) & $3 e-19$ & Myc_N & \\
\hline & AM697688 & Q9DB43: Zinc finger protein-like I (Mus musculus) & $2 e-36$ & Zinc finger, RING-type & \\
\hline & AM697690 & Q08043: Alpha-actinin-3 (Homo sapiens) & le-132 & $\mathrm{CH}$ & AAAY-59-05-E \\
\hline & $\overline{\mathrm{AM} 697691}$ & Q9PU47: Alpha-actinin-associated LIM protein (Bos taurus) & $7 e-07$ & PDZ & \\
\hline & AM697692 & Q3SYZ8: Alpha-actinin-associated LIM protein (Gallus gallus) & $2 e-05$ & PDZ & \\
\hline \multicolumn{6}{|c|}{ Apoptosis/Signaling } \\
\hline & AM697693 & Q98943: Caspase-2 precursor (Gallus gallus) & $6 e-08$ & CARD & \\
\hline \multicolumn{6}{|c|}{ Protein and DNA biosynthesis } \\
\hline & AM697695 & AAH76954: Polymerase (DNA directed), alpha 2 (Xenopus tropicalis) & $1 \mathrm{e}-39$ & DNA_pol_E_B & AAAY-62-10-B \\
\hline & AM697696 & P0720I: Ribonucleoside-diphosphate reductase small chain (Spisula solidissima) & $4 e-40$ & Ribonuc_red_sm & AAAY-66-2I-F \\
\hline & AM697697 & AAV34860: ribosomal protein S4 (Bombyx mori) & $6 e-19$ & RS4NT & $48-I-06-D$ \\
\hline & AM697698 & P69091: 60S ribosomal protein LI8 (Oreochromis niloticus) & $2 e-56$ & Ribosomal_LI8e & \\
\hline & $\overline{\mathrm{AM} 697699}$ & P23403: 40S ribosomal protein S20 (Xenopus laevis) & $6 e-52$ & Ribosomal_SIO & AAAY-68-04-F \\
\hline \multicolumn{6}{|c|}{ Respiratory-chain } \\
\hline & AM697700 & $\begin{array}{l}\text { Q8HXQ9: NADH-ubiquinone oxidoreductase } 5 \text { I kDa subunit, mitochondrial } \\
\text { (Macaca fascicularis) }\end{array}$ & le-60 & ComplexI_5IK & AAAC-4I-02-C \\
\hline \multicolumn{6}{|c|}{  } \\
\hline & AM69770I & P25083: mitochondrial ADPIATP translocator (Solanum tuberosum) & $8 e-63$ & Mito_carr & AAAD-4I-05-D \\
\hline & AM697702 & P98198: phospholipid-transporting ATPase (Homo sapiens) & $4 e-59$ & ATPase, EI-E2 type & \\
\hline & $\overline{\mathrm{AM} 697703}$ & Q6B865: ATP synthase c-subunit (Ixodes pacificus) & $2 e-37$ & ATP-synt_C & AAAY-48-20-H \\
\hline & $\overline{\mathrm{AM} 697704}$ & Q9UN76: Amino acid transporter ATB0+ (Homo sapiens) & le-33 & SNF & \\
\hline \multicolumn{6}{|c|}{ Endosomal sorting } \\
\hline & AM697705 & Q6NWF4: Vacuolar protein sorting protein 25 (Danio rerio) & 0.61 & & \\
\hline \multicolumn{6}{|c|}{ Unknown functions } \\
\hline & AM697706 & Q4PAT4: Hypothetical protein (Ustilago maydis) & le-16 & & \\
\hline & AM697707 & P53858: Protein BNI4 (Saccharomyces cerevisiae) & 0.1 & & \\
\hline & $\overline{\mathrm{AM} 697686}$ & Hypothetical protein & NSMI & & \\
\hline & AM697689 & Hypothetical protein & NSM & & \\
\hline & AM697694 & Hypothetical protein & NSM & & \\
\hline & AM697679 & Cationic $\alpha$-helical putative antimicrobial peptide & NSM & & \\
\hline & AM697680 & Disulfide bridged $\alpha$-helical putative antimicrobial peptide & NSM & & \\
\hline
\end{tabular}

'NSM, no significant match 


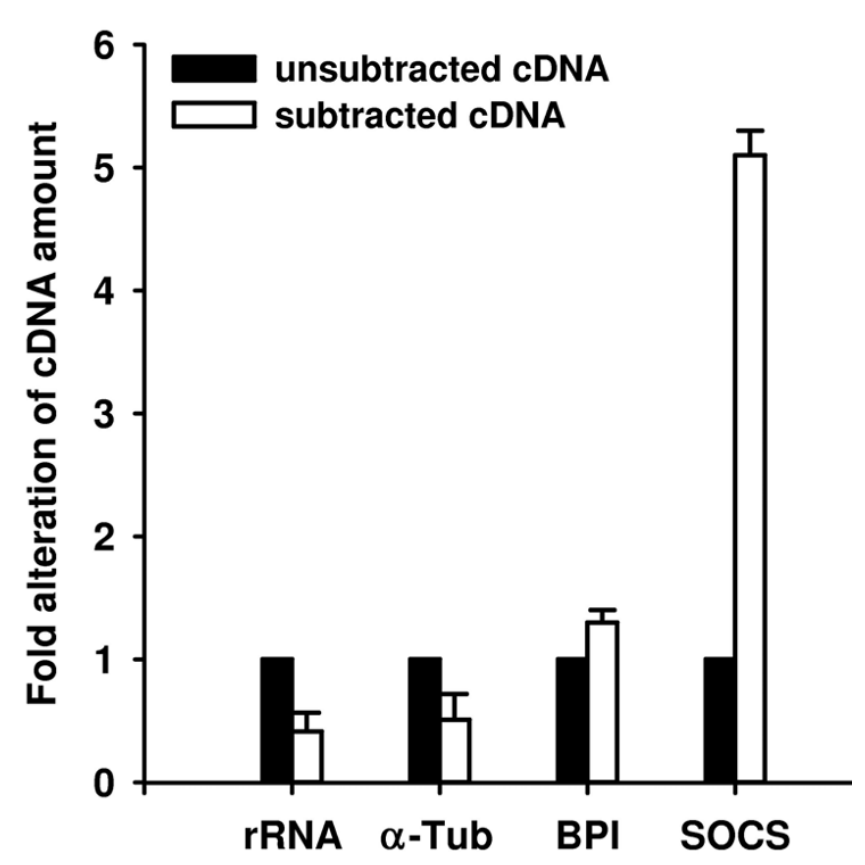

Figure I

Confirmation of the enrichment of immune-related transcripts in the subtracted cDNA library by quantitative real-time PCR analysis. The relative amount of cDNAs of $18 \mathrm{~S}$ rRNA, $\alpha$-tubulin, BPI, and SOCS in the subtracted cDNA library (white bars) is shown relative to their amount in unsubtracted cDNA library (black bars). The cDNA amount of the house-keeping genes $18 \mathrm{~S}$ rRNA and $\alpha$ tubulin were reduced about 2.5 fold by the subtraction procedure. In contrast, potentially immunity-related genes BPI and SOCS were found to be I.3 and 5.I fold enriched in the subtracted cDNA library, respectively. Results represent mean values of three independent determinations \pm S.D.

Transcription) pathway that is required for cellular proliferation, stem cell maintenance and immune responses in both vertebrates and invertebrates [20,21]. In addition, it was shown for human SOCS-1 that it is involved in negative regulation of Toll-like receptor signaling [22].

Some among the identified sequences encode Platynereis proteins that contain an arrestin domain or share



\section{Figure 2}

Sequence alignment of potential Platynereis CD35 with human CD35. The partial sequence of the putative CD35 from Platynereis (AM69768I), was aligned with the amino-terminal sequence from human CD35 (Hsap-CD35, NP_000642). Red color indicates $80 \%$ consensus and blue color $50 \%$ consensus. sequence similarities to alpha-actinin-3 and alphaactinin-associated proteins, respectively. Arrestins were originally characterized as structural adaptor proteins that modulate the desensitization and trafficking of sevenmembrane-spanning $G$ protein coupled receptors and that have also been implicated in endocytosis of receptors and in crosstalk with other signaling pathways [23]. Alpha-actinin is a F-actin cross-linking protein that anchors actin to a variety of intracellular structures and is present in focal adhesion complexes [24]. Through these complexes integrins are able to transduce bi-directional signals between the extracellular matrix and intracellular signaling pathways essentially involved in cell shape change and motility of e.g. immune cells.

Interestingly, we further determined the induced expression of a protein with sequence similarities to the protooncogene myc (Fig. 3A) which is an important regulator of apoptosis in mammals. Phylogenetic analysis revealed that the Platynereis myc exhibits a higher relation to the human c-myc than to other analyzed myc homologues (Fig. 3B). The determined c-myc expression in activated human macrophages [25] reflects the need of a finely tuned balance between cell proliferation, cell division arrest, and apoptosis in the vertebrate immune cells [26]. Consistently with the importance of apoptosis regulation, we found immune-induction of potential homologues of caspase- 2 and of the adenine nucleotide (ADP/ATP) translocator: (i) Caspase-2 is a member of a family of evolutionarily conserved cysteinyl proteases that mediate both apoptosis and inflammation through aspartate-specific cleavage of cellular substrates [27,28]; (ii) (ADP/ATP) translocator is an element of the mitochondrial permeability transition pore. This protein complex induces a sudden increase in permeability of the mitochondrial membrane resulting in cytochrome $\mathrm{C}$ release which is a key element in cell death [29].

\section{Effector molecules}

We identified several transcripts of factors essentially involved in cell proliferation and in protein biosynthesis including the alpha-DNA polymerase, ribonucleoside reductase and several ribosomal proteins. This is plausible since production of effector molecules depends on the activation of cellular proliferation and translation and is commonly found in comparative analysis of innate immune responses $[4-7,11,12,15]$.

In addition, the immune-induced expression of following effector molecules were documented in P. dumerilii: (I) $\alpha$ amylases are able to hydrolyze 1,4-alpha-D-glucosidic linkages in oligo- and polysaccharides and belong to a multigene family [30]. Confirming their potential antimicrobial activity human salivary $\alpha$-amylase has been reported as an effective inhibitor of Neisseria gonorrhoeae 
A

Platynereis

SLCN----T-----DVSVSTTVCVNPQSVFPYPL-NDGE-AANST---NLELDTPS---DS--

Human_C-MYC SGSPNPA-RGHSVCS----TSSLYLQDLSAAASECIDPSVVFPYPL-NDSS-SPKSCASQDSSAFSPS--SDSLI Human_N-MYC AGAASPAGRGHGGAAGAGRAGAALPAELAHPAAECVDPAVVF'PFPV-NKREPAPVPAAPASAPAAGPAVASGAGI Human_MYC-L APRGNPP-KA-SAAP-_-_-_-_--DCT-PSLFAGNPAPAAPCPL-GE----PKTQACSGSE--SPS---DS-Strongylo. RLTAHSSVAG-GVSG-_-_-_-_-_DFS--SSECVDPTSVEPYPL-SDTRLDFSSTTPSDSEEEIDVVTVEKKC Caenorhab. FLFGGNNTPGGFKMSG-TTSGVPTLSQRLEQPPISRTSTIFG-NVENKPERIFTSLTSQNTPTPSPLDISSLSR Drosophil. MVDDGPNLETPSDSDE--EIDVVSYTDKKLPTNPSCHLMGALQFQMAHKISIDHMKQKPRYNNENLPYTPASS--

Platynereis ENDDDDD---_--_-----DDDDDDDVEE--EE-----EFEIEFDDEDDEEIDVVSVSERHGPISDHRYTA---Human_C-MYC SSTESSP-_-_-_-_-_-_QGSPEPLVLH--EETPPTTSSDSEFEQEDEFEIDVVSVEKRQAPGKRSESGS---Human_N-MYC APPAGAPGVAPPRPGGRQTSGGDHKALSTSGEDTLSDSDDEDDEEEDEEEEIDVVTVEKRRSSSNTKAVTTFTIT Human_MYC-I Strongylo. Caenorhab. IRTSSLNESW---KMSHIVEGSPTYQAFAASVTTKPSILESPSTSGDISGPASVPVQASQHPPKIITPPSA---Drosophil. SPVKSVANSRYPSPSSTPYQNCSSASPSYSPLSVDSSNVSSSSSSSSSQSSFTTSSSNKGRKRSSLKDPGLLISS

Platynereis ----TVA--_-_-_--PAVSV--SAHVAA-MHNYTAPHPTTI-KSEPVSPASSP

Human_C-MYC ----PSAGGHSKPPHSPLVLK--RCHVSTHOHNYAAP-PSTR-KDYPAAKRVKLD-SVRVLRQ-ISNNRKCTSPR Human_N-MYC VRPKNAALGPGRAQSSELILK--RCLPIHQOHNYAAPSPYVESEDAPPQKKIKSEASPRPLKSVIPPKAKSLSPR Human_MYC-I -----AA---_-----REPPE--SC--SQEFASERGPQEEVLERDAAGEKEDEFDEEIVSPPPVESEAAQSCHPK Strongylo. ----TTGL-----KKLNKINL--AKHVSLEDVKRVLENTLSSNNSTKHSKSLSKRTYNRNSSRGRS-RGSSRHGS Caenorhab. ---SSKRKEQEAAMAPLVNRQQSCDVNLLNGKMAVKVEEKSGRHYLPTTPTELKEVTKEFPLIMSAPSSVKSMR Drosophil. SSVYLPGVNNKVTHSSMMSKK--SRGKKVVGTSSGNTSPISSGQDVDAMDRNWQRRSGGIATSTSSNSSVHRKDF

B



\section{$\underline{0.1}$}

Figure 3

Alignment and phylogenetic analysis of the myc oncogene. (A) The partial protein sequence of myc from $P$. dumerilii (AM697687) was aligned with corresponding sequences from S. purpuratus (NP_999744), D. melanogaster (Q9W4S7), C. elegans (NP_001022773), human c-myc (P0I I06), and human n-myc (I 202343A). The human myc-like protein (NP_00I028253) was used as out-group. Red color indicates $70 \%$ consensus and blue color $40 \%$ consensus. (B) A Bayesian protein tree generated using the aligned protein sequences revealed that Platynereis myc shows highest relation to human c-myc. Posterior probabilities are plotted at the nodes. The scale bar represents the substitutions per site according to the model of amino acid evolution applied. 
in vitro [31]. (II) One deduced protein exhibits sequence similarities to the serine protease inhibitors of the migratory locust Locusta migratoria [32]. Many serine proteinase inhibitors have evolved in vertebrates and invertebrates to regulate vital serine proteinase cascades including melanisation [33,34], hemostasis, or complement system $[35,36]$. (III) We identified one protein sharing sequence similarities to a family of immune-induced proteins from insects with not yet elucidated function [15,37]. These proteins contain a reeler domain that is also present in human reelin and stromal cell derived factor receptor 2 homologue. (IV) Ferritin serves as an evolutionarily conserved molecule for the iron-withholding strategy in innate immunity [38] and is strongly induced after immune-challenge in vertebrates and invertebrates $[39,40]$. Accordingly, we identified transcripts encoding two related ferritin subunits from Platynereis. Alignment and phylogenetic analysis of the ferritin isoforms revealed that $P$. dumerilii ferritin 1 groups near to known ferritins from the sponge Suberites domuncula and from the sea urchin $S$. purpuratus whereas the second isoform groups near to the ferritins from Hydra and Drosophila (Fig. 4). The obtained phylogenetic tree needs careful interpretation, but implicates at least that the identified $P$. dumerillii ferritins represent orthologous genes that arose during early animal evolution whereas ferritins from Caenorhabditis, Drosophila and human are obviously encoded by paralogous genes, and ferritin gene duplications occurred independently in different lineage bifurcations. Interestingly, Drosophila ferritins are secreted proteins [38] that exhibit highest deviation in sequence when compared with other analyzed ferritins. In contrast, vertebrate ferritins are localized in the cytoplasm and in mitochondria whereas the plant ferritin is localized in chloroplasts. (V) We found a protein sharing highest sequence similarities with bactericidal permeability-increasing proteins (BPI) from other organisms (Fig. 5). BPI has been recognized to play an important role in innate immunity against Gramnegative bacteria by direct microbicidal and by endotoxinneutralizing action $[41,42]$. In humans, several isoforms of BPI are present and form a protein family to which lipopolysaccharide-binding protein (LBP), cholesteryl ester transfer protein (CETP), and phospholipid transfer protein (PLTP) also belong [43]. A phylogentic analysis of the Platynereis BPI sequence with counterparts from other animals determined highest similarity to BPI from C. elegans. (VI) Several identified transcripts encode hypothetical proteins with no significant blastX match, but two of them exhibit features of antimicrobial peptides [44]. For example, a cationic and a hydrophobic peptide with predicted $\alpha$-helical structures were identified. The latter has cysteine residues that may form disulfide bridges (Fig. 6).

\section{Quantitative real-time RT-PCR analyses}

In order to precisely quantify gene expression of selected genes, we used real-time RT-PCR and total RNA from LPSinjected and untreated animals (Fig. 7). In Platynereis, we found that the transcriptional rates of myc were induced about 1.6 fold, of SOCS about 8 fold, and of BPI over 16 fold in response to immune challenge. In contrast, the expression of the house-keeping gene $18 \mathrm{~S}$ rRNA was not influenced by the treatment.

\section{Conclusion}

In order to elucidate immune responses from a lophotrochozoan model organism that has been recognized as a slow-evolving Bilateria, we analyzed the immune-related transcriptome of the marine annelid $P$. dumerilii. Using the suppression subtractive hybridization method we identified 35 genes encoding proteins potentially involved in Platynereis immunity. Comparison with the EST database of $P$. dumerilii [45] revealed that $70 \%$ of the clusters represent novel genes, although 21,762 EST clones with an average length of 1,277 base pairs were available. This confirms the suitability of the used method and increases the number of identified genes from this polychaete.

The immune-induced expression of myc, SOCS, and BPI was confirmed by quantitative real-time RT-PCR analyses. In addition, phylogenetic analyses implicate that Platynereis immunity-related genes are more related to counterparts from Deuterostomia than are those from Ecdysozoa (e.g. Drosophila and Caenorhabditis). Furthermore, in the case of BPI no protein with sequence similarities is present in the fully sequenced genome from $D$. melanogaster, whereas proteins from humans, sea urchin, and Caenorhabditis exhibit significant sequence similarities to the identified homologue from Platynereis. Taken together, these findings are in line with recent reports that validate that $P$. dumerilii and human genes are evolutionarily more primary in structure and sequence than are those of fast-evolving animals where these initially complex genes have been secondarily simplified in some cases $[8,9]$. In conclusion, our results regarding the immuneinduced genes from Platynereis will be a valuable resource for subsequent polychaete specific immune studies in particular and comparative lophotrochozoan/bilaterian immune studies in general.

\section{Methods \\ Immune challenge of adult Platynereis dumerilii and RNA isolation}

Adult Platynereis dumerilii (strain Berlin) were obtained from H.-D. Pfannenstiel, Institute of Biology, Free University of Berlin, Germany. $10 \mu \mathrm{l}$ sample volume, corresponding to $1 \mu \mathrm{g}$ LPS (purified Escherichia coli endotoxin 0111:B4, Cat. No.: L2630, Sigma, Taufkirchen, Germany) 


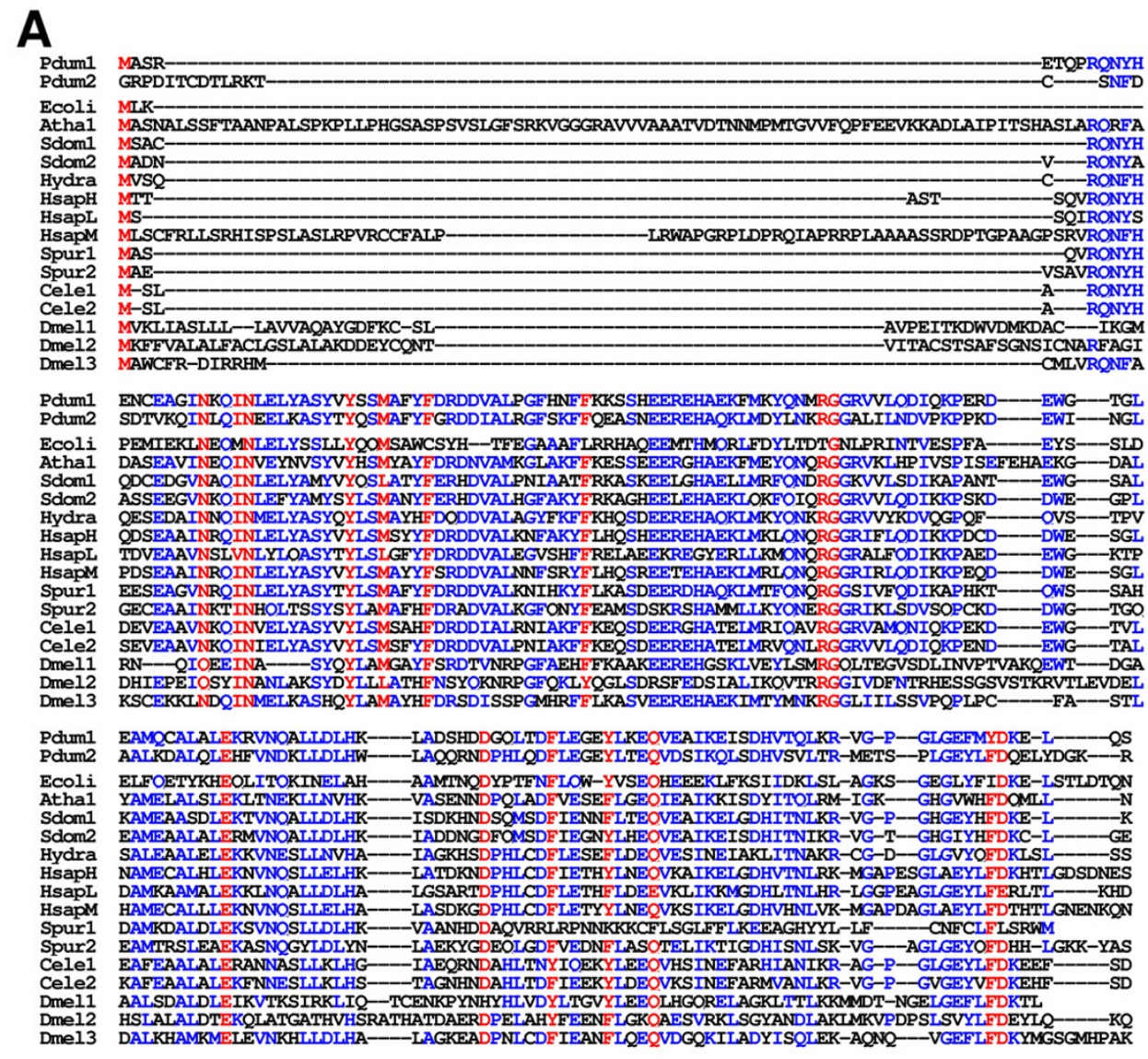

B

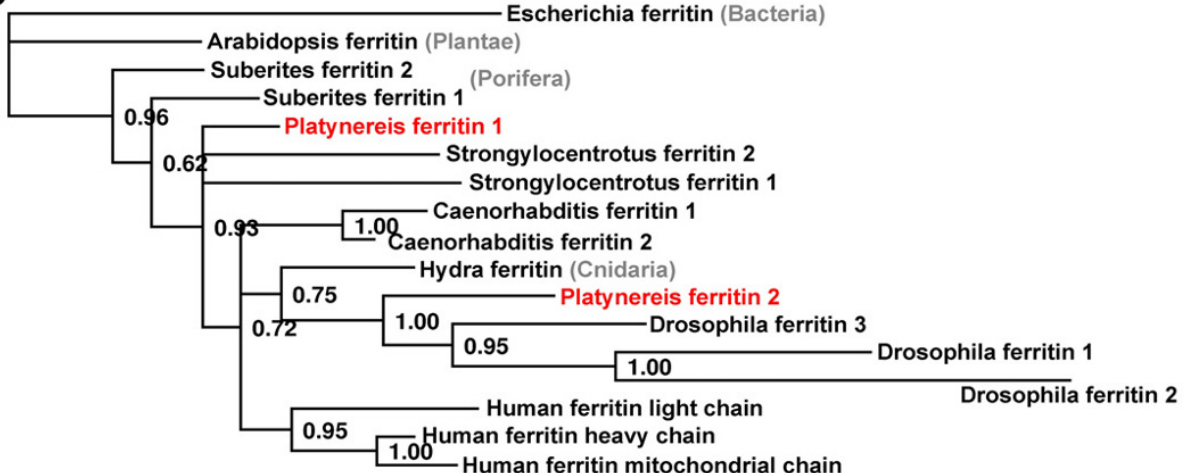

$\underline{0.1}$

Figure 4

Alignment and phylogenetic analysis of the ferritin isoforms. (A) The protein sequences of the identified ferritin subunits from P. dumerilii (Pdum-I, AM697674; Pdum-2, AM697675) were aligned with corresponding sequences from H. sapiens (Ferritin heavy chain, P02794; light chain, P02792; mitochondrial ferritin, Q8N4E7), S. purpuratus (Spur I, XP_00I I84706; Spur2, XP_796I52), D. melanogaster (DmelI, NP_524873; Dmel2, AAF07879; Dmel3, NP_572854), C. elegans (Cele I, NP_504944; Cele2, NP_49I I98), Suberites domuncula (Sdom I, CAC84556; Sdom2, CAC84555), Hydra vulgaris (Hydra, ABC25029), Arabidopsis thaliana (Athal, NP_195780), and Escherichia coli (Ecoli, NP_4I64I8). Red color indicates $90 \%$ consensus and blue color $40 \%$ consensus. (B) A Bayesian protein was generated using aligned ferritin sequences including bacterial ferritin from E. coli as out-group. This analysis revealed that Platynereis ferritin I group near to ferritins from the sponge Suberites domuncula and the sea urchin S. purpuratus whereas the Platynereis ferritin 2 isoform groups near to the ferritins from Hydra and Drosophila. Posterior probabilities are plotted at the nodes. The scale bar represents the substitutions per site according to the model of amino acid evolution applied. 
A



B

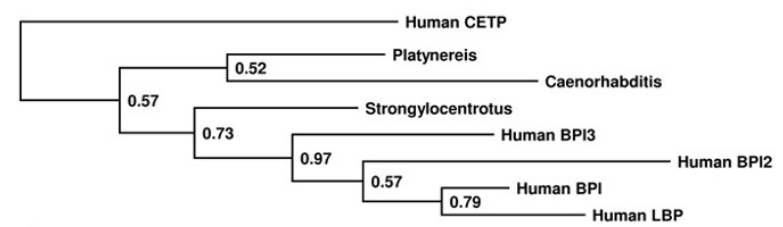

$\underline{0.1}$

Figure 5

Sequence alignment of the potential Platynereis BPI with homologues from other organisms. (A) The partial sequence of the BPI from $P$. dumerilii (Platynereis, AM697673), was aligned with sequences from $C$. elegans (Caenorhab., NP_510689), from S. purpuratus (Strongylo., XP_00I I92950), and from Homo sapiens (Human_BPI, NP_0017I6; Human_BPI2, NP_777592; Human_BPI3, NP_079503; Human_LBP, NP_004I30) As out-group we used human cholesteryl ester transfer protein

(Human_CETP, NP_000069). Red color indicates $80 \%$ consensus and blue color $40 \%$ consensus. (B) A Bayesian protein tree was generated using the aligned region of proteins and we found that Platynereis BPI exhibit highest relation to the $C$. elegans BPI. However, the analysis reveals that BPI from $P$. dumerilii is more ancestral in sequence when compared to BPI from $C$. elegans. Posterior probabilities are plotted at the nodes. The scale bar represents the substitutions per site according to the model of amino acid evolution applied.

per animal were injected dorsolaterally into the coelom using $1 \mathrm{ml}$ disposable syringes and $0.4 \times 20 \mathrm{~mm}$ needles mounted on a microapplicator. $8 \mathrm{~h}$ post injection animals were homogenized in liquid $\mathrm{N}_{2}$ and total RNA was extracted using the Qiagen RNeasy kit according to the instructions of the manufacturers. RNA integrity was confirmed by ethidium bromide gel staining and quantities were determined spectrophotometrically [46].

\section{Construction of a subtracted cDNA library using the SSH method}

In order to identify differentially expressed genes during immune response the SSH method was performed using RNAs from immune-challenged and control animals, the SMART PCR cDNA synthesis Kit (Clontech, Mountain View, CA, USA), and the PCR-Select cDNA subtraction Kit (Clontech), according to the protocols of the manufacturer.

\section{Colony PCR and blot hybridization}

Colony PCR was performed on 288 randomly picked colonies with vector specific primers T7-promotor: 5'TAATACGACTCACTATAGGG-3' and SP6: 5'-ATTTAGGT-

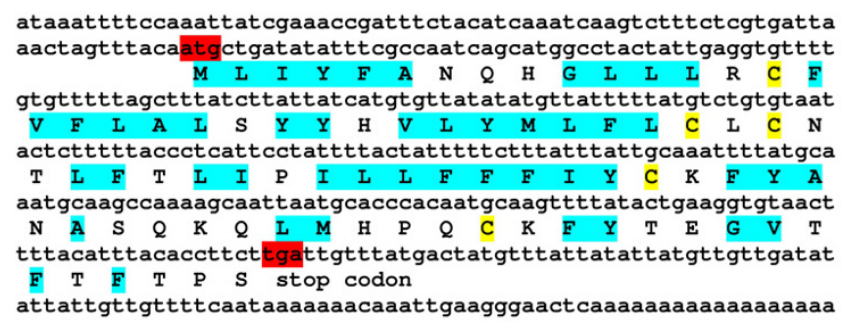

Figure 6

CDNA sequence and deduced amino acid sequence of a putative antimicrobial peptide from $P$. dumerilii. The identified cDNA of a putative antimicrobial peptide (AM697680) is shown including the deduced protein sequence. Start and stop codons are indicated by red shading, hydrophobic amino acids by gray shading and cysteine residues potentially involved in disulfide bridging by yellow shading.

GACACTATAG-3' (purchased from Thermo electron, Waltham, MA, USA) using a Biometra PCR cycler and the Red Taq PCR system (Sigma, Taufkirchen, Germany). Used PCR conditions were: denaturation at $95^{\circ} \mathrm{C}$ for 3 min followed by 30 cycles of denaturation at $95^{\circ} \mathrm{C}$ for 15 s, annealing at $43^{\circ} \mathrm{C}$ for $15 \mathrm{~s}$, and extension at $72^{\circ} \mathrm{C}$ for $60 \mathrm{~s}$. A final $7-\min 72^{\circ} \mathrm{C}$ step was added to allow complete extension of the products. $1 \mu \mathrm{l}$ of resulting PCR products were identically spotted onto two sheets of positively charged nylon membranes (Roche, Lewes, United Kingdom). Membranes were dried and UV cross-linked using a BioRad UV cross-linker (BioRad, München, Germany), according to the instructions of the manufacturer. Digoxigenin labeled probes for hybridization were generated using secondary PCR products of subtracted and non-subtracted cDNAs and the Dig-High Prime Labelling kit (Roche, Lewes, United Kingdom). Hybridization, washing, and detection of digoxigenin labeled DNA was performed in accordance to the user guide instructions of the Dig Easy Hyb Granules, Dig-Wash and Block Buffer Set, Anti-Digoxigenin-AP and NBT/BCIP ready-to-use tablets (Roche, Lewes, United Kingdom).

\section{Sequencing and computer analysis of CDNA sequence data} Plasmid isolation of 140 positively screened colonies was performed with the Fast MiniPrep kit (Eppendorf, Hamburg, Germany) and purified plasmids were custom sequenced by Macrogen Inc. (Seoul, South-Korea). Sequences were used to identify similar sequences of SWISS-PROT protein sequence database (available at the National Center for Biotechnology Information) using BLASTX program (BLASTX 2.2.13) [47]. InterProScan [48] was used for an integrated search in PROSITE, Pfam, and PRINTS databases at EMBL-European Bioinformatics Institute and to predict signal sequences and transmembrane regions. 


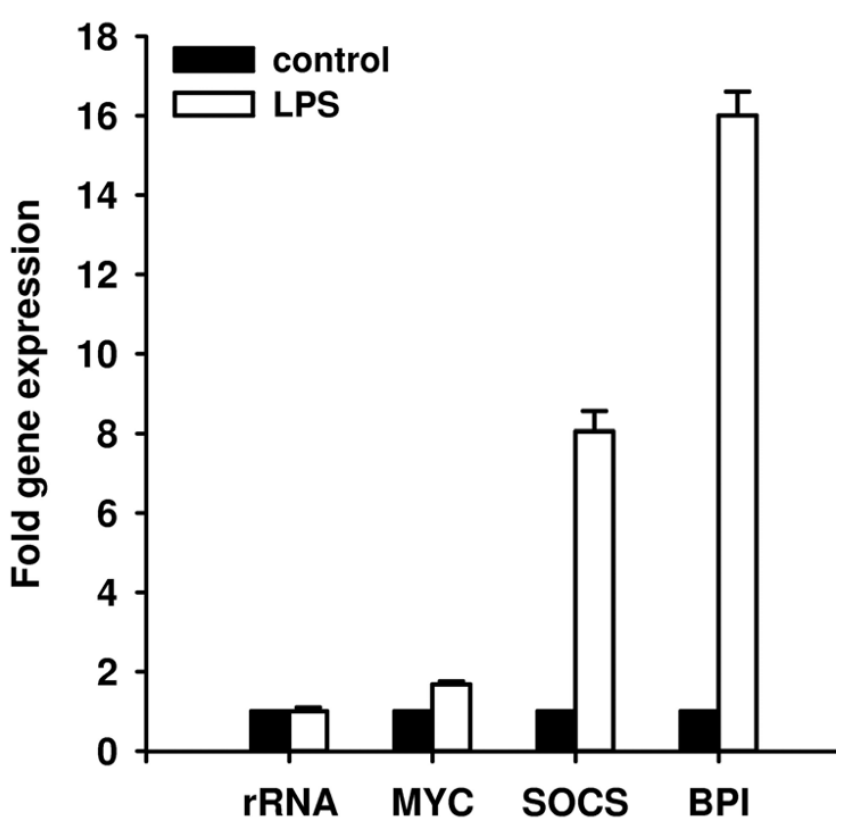

Figure 7

Quantitative real-time RT-PCR analysis of transcriptional levels of selected Platynereis genes in response to immune challenge. The mRNA levels of selected genes in immune challenged animals (black bars) were determined and are shown relative to their expression levels in untreated animals (white bars). The transcription rates of myc, SOCS, and BPI genes were found to be increased over I.6, 8, and 16 fold, respectively, in response to LPS injection. In contrast, the amount of I $8 \mathrm{~S}$ rRNA transcripts were not significantly influenced. Results represent mean values of three independent determinations \pm S.D.

\section{Quantitative real-time PCR}

Quantitative PCR was performed with the real-time PCR system Mx3000P (Stratagene, La Jolla, California, USA) using the FullVelocity SYBR ${ }^{\circledR}$ Green QRT-PCR Master Mix (Stratagene), according to the protocols of the manufacturer. In order to confirm the subtraction efficiency of constructed cDNA library 1 ng of unsubtracted and subtracted cDNA, respectively, was used to amplify $18 \mathrm{~S}$ rRNA, $\alpha$-tubulin, BPI, and SOCS. Used primers were: $18 \mathrm{~S}$ rRNAforward: 5'-ATGGTTGCAAAGCTGAAACT-3', 18 S rRNAreverse: 5'-TCCCGTGTTGAGTCAAATTA-3', the universal primers $\alpha$-tubulin-forward: 5'-GCCAACCAGATGGTCAA3 ' and $\alpha$-tubulin-reverse: 5'-GCTTGGTCTTGATGGTG-3', BPI-forward: 5'-TTCAAGCAAGGTCCGTCCAA-3', BPIreverse: 5'-CCTGCTTCCAGCCATCCATC-3', SOCS-forward: 5'-CAGATGGCCTGCAGGTACCAA-3', and SOCSreverse: 5'-TCGAGTCAATGCCACTGTCCA-3'. For gene expression analyses, we used $100 \mathrm{ng}$ total RNA per well and primers described above. In addition, primers MYCforward: 5'-GCCCCTGCAGTTTCAGTTTCA-3' and MYC- reverse: 5'-TGGGGAGACAGGTTCGGATTT-3' were used to amplify myc transcripts.

\section{Sequence alignments and phylogenetic analyses}

Sequence alignments were computed using the blosum 62 algorithm $[49,50]$. For phylogenetic reconstruction, we used the software package MrBayes 3.1.2 [51], which combines Bayesian inference and Markov chain Monte Carlo convergence acceleration techniques known as Metropolis coupling. The best fixed-rate model of amino acid evolution was determined by model jumping among nine possible models. The model with the overall highest posterior probability was Jones model [52] for the myc protein after $5 \times 10^{6}$ generations and blosum62 model [53] for BPI after $10^{6}$ generations and also for ferritins after $10^{6}$ generations. We used convergence diagnostic (i.e., the standard deviation of split frequencies) to determine whether the run length is sufficient. The average standard deviation of split frequencies was 0.0021 for BPI, 0.0049 for the ferritins, and 0.00024 for the myc, respectively. This indicated that the two chains that were run converged on similar results in all cases. The $50 \%$ majority rule tree presented here was constructed from all sampled trees with the first $25 \%$ of all trees ignored as burn in. Trees were visualized with TREEVIEW 1.6.6 [54]. Posterior probabilities plotted at the nodes can be interpreted as the probability that the tree or clade is correct [55].

\section{Competing interests}

The author(s) declare that they have no competing interests.

\section{Authors' contributions}

BA designed and carried out the experiments, performed the analyses, and drafted parts of the manuscript. AV injected the animals, participated in its design and coordination, and drafted parts of the manuscript. All authors read and approved the final manuscript.

\section{Acknowledgements}

We thank Meike Fischer (University of Giessen) for excellent technical assistance and Katja Altincicek for critical reading of the manuscript. We are grateful to H.-D. Pfannenstiel (Free University of Berlin, Germany) for supporting us with animals and Detlev Arendt (EMBL Heidelberg, Germany) for providing access to the Platynereis EST database. The authors acknowledge financial support from the Justus-Liebig-University of Giessen to $B A$ and from the Deutsche Forschungsgemeinschaft to AV.

\section{References}

I. Cooper EL: Comparative immunology. Integrative Zoology 2006, I:32-43.

2. Lemaitre B, Hoffmann JA: The host defense of Drosophila melanogaster. Annu Rev Immunol 2007, 25:697-743.

3. Kim DH, Ausubel FM: Evolutionary perspectives on innate immunity from the study of Caenorhabditis elegans. Curr Opin Immunol 2005, 17:4-10.

4. Lefebvre C, Cocquerelle C, Vandenbulcke F, Hot D, Huot L, Lemoine $Y$, Salzet M: Transcriptomic analysis in the leech Theromyzon tessulatum : involvement of cystatin B in innate immunity. Biochem J 2004, 380:617-625. 
5. Tanguy A, Guo X, Ford SE: Discovery of genes expressed in response to Perkinsus marinus challenge in Eastern (Crassostrea virginica) and Pacific (C. gigas) oysters. Gene 2004, 338: | 2 I-|3| 6. Guillou F, Mitta G, Galinier R, Coustau C: Identification and expression of gene transcripts generated during an anti-parasitic response in Biomphalaria glabrata. Dev Comp Immunol 2007, 31:657-67I.

7. Bouchut A, Coustau C, Gourbal B, Mitta G: Compatibility in the Biomphalaria glabrata/Echinostoma caproni model: new candidate genes evidenced by a suppressive subtractive hybridization approach. Parasitology 2007, 134:575-588.

8. Arendt D, Tessmar-Raible K, Snyman H, Dorresteijn AW, Wittbrodt ]: Ciliary photoreceptors with a vertebrate-type opsin in an invertebrate brain. Science 2004, 306:869-87।.

9. Raible F, Tessmar-Raible K, Osoegawa K, Wincker P, Jubin C, Balavoine G, Ferrier D, Benes V, de Jong P, Weissenbach J, Bork P, Arendt D: Vertebrate-type intron-rich genes in the marine annelid Platynereis dumerilii, Science $2005,310: 1325-1326$.

10. Rast JP, Smith LC, Loza-Coll M, Hibino T, Litman GW: Genomic insights into the immune system of the sea urchin. Science 2006 31 4:952-956

II. Altincicek B, Vilcinskas A: Identification of immune-related genes from an apterygote insect, the firebrat Thermobia domestica. Insect Biochem Mol Biol 2007, 37:726-73I.

12. Oduol F, Xu J, Niare O, Natarajan R, Vernick K: Genes identified by an expression screen of the vector mosquito Anopheles gambiae display differential molecular immune response to malaria parasites and bacteria. Proc Natl Acad Sci USA 2000, 97: | |394-1| 402

13. Hao Z, Kasumba I, Lehane MJ, Gibson WC, Kwon J, Aksoy S: Tsetse immune responses and trypanosome transmission: implications for the development of tsetse-based strategies to reduce trypanosomiasis. Proc Natl Acad Sci USA 200I, 98: 12648- 12653

14. Seitz V, Clermont A. Wedde M, Hummel M, Vilcinskas A, Schlatterer $\mathrm{K}$, Podsiadlowski L: Identification of immunorelevant genes from the greater wax moth (Galleria mellonella) by a subtractive hybridization approach. Dev Com Immunol 2003, 27:207-215.

15. Zhu Y, Johnson T, Myers A, Kanost M: Identification by subtractive suppression hybridization of bacteria-induced genes expressed in Manduca sexta fat body. Insect Biochem Mol Biol 2003 33:54I-559.

16. Lin B, Chen S, Cao Z, Lin Y, Mo D, Zhang H, Gu J, Dong M, Liu Z, Xu $A$ : Acute phase response in zebrafish upon Aeromonas salmonicida and Staphylococcus aureus infection: Striking similarities and obvious differences with mammals. Mol Immunol 2007, 44:295-30I.

17. Gasque P: Complement: a unique innate immune sensor for danger signals. Mol Immunol 2004, 4 I: 1089-1098.

18. Nonaka M. Kimura A. Genomic view of the evolution of the complement system. Immunogenetics 2006, 58:70I-7/3.

19. Gao JL, Kuhns DB, Tiffany HL, McDermott D, Li X, Francke U, Murphy PM: Structure and functional expression of the human macrophage inflammatory protein I alpha/RANTES receptor. J Exp Med 1993, 177: 1421-1427.

20. Rawlings JS, Rennebeck G, Harrison SM, Xi R, Harrison DA: Drosophila suppressors of cytokine signaling (SOCS) differentially regulate JAK and EGFR pathway activities. BMC Cell Biol 2004, 5.38

21. Alexander WS, Hilton DJ: The role of suppressors of cytokine signaling (SOCS) proteins in regulation of the immune response. Annu Rev Immunol 2004, 22:503-529.

22. Mansell A, Smith R, Doyle SL, Gray P, Fenner JE, Crack PJ, Nicholson SE, Hilton DJ, O'Neill LA, Hertzog PJ: Suppressor of cytokine signaling I negatively regulates Toll-like receptor signaling by mediating Mal degradation. Nat Immunol 2006, 7:148-155.

23. Wang $Y$, Tang $Y$, Teng L, Wu Y, Zhao X, Pei G: Association of betaarrestin and TRAF6 negatively regulates Toll-like receptorinterleukin I receptor signaling. Nat Immunol 2006, 7: 139-147.

24. Sepulveda JL, Wu C. The parvins. Cell Mol Life Sci 2006, 63:25-35.

25. Dror N, Alter-Koltunoff M, Azriel A, Amariglio N, Jacob-Hirsch J, Zeligson S, Morgenstern A, Tamura T, Hauser H, Rechavi G, Ozato K, Lev BZ: Identification of IRF-8 and IRF-I target genes in activated macrophages. Mol Immunol 2007, 44:338-346.

26. Xaus J, Comalada M, Valledor AF, Cardo M, Herrero C, Soler C Lloberas J, Celada A: Molecular mechanisms involved in macrophage survival, proliferation, activation or apoptosis. Immunobiology 200I, 204:543-550

27. Lamkanfi M, D'hondt K, Vande Walle L, van Gurp M, Denecker G, Demeulemeester J, Kalai M, Declercq W, Saelens X, Vandenabeele $P$. A novel caspase-2 complex containing TRAF2 and RIPI. I Biol Chem 2005, 280:6923-6932.
28. Lamkanfi M, Festjens N, Declercg W, Berghe TV, Vandenabeele P: Caspases in cell survival, proliferation and differentiation. Cell Death Differ 2007, 14(1):44-55.

29. Newmeyer DD, Ferguson-Miller S: Mitochondria: releasing power for life and unleashing the machineries of death. Cell 2003, I I 2:48I-490.

30. Stam MR, Danchin EG, Rancurel C, Coutinho PM, Henrissat B: Dividing the large glycoside hydrolase family 13 into subfamilies: towards improved functional annotations of \{alpha\}-amylaserelated proteins. Protein Eng Des Sel 2006, 19:555-562.

31. Mellersh A, Hafiz S, McEntegart MG, Geary I: Induction of a cell wall variant of the gonococcus by human amylase. $\mathrm{Br} J$ Vener Dis 1980, 56:230-234

32. Boigegrain RA, Mattras H, Brehelin M, Paroutaud P, Coletti-Previero $M A$ : Insect immunity: two proteinase inhibitors from hemolymph of Locusta migratoria. Biochem Biophys Res Commun 1992, 189:790-793.

33. Theopold U, Schmidt O, Soderhall K, Dushay MS: Coagulation in arthropods: defence, wound closure and healing. Trends Immunol 2004, 25:289-294.

34. Kanost MR: Serine proteinase inhibitors in arthropod immunity. Dev Comp Immunol 1999, 23:291-30I.

35. Hughes AL, Yeager M: Molecular evolution of the vertebrate immune system. Bioessays 1997, 19:777-786.

36. Pike RN, Buckle AM, le Bonniec BF, Church FC: Control of the coagulation system by serpins. Getting by with a little help from glycosaminoglycans. FEBS J 2005, 272:4842-485I.

37. Veiga $A B$, Ribeiro JM, Guimaraes JA, Francischetti IM: A catalog for the transcripts from the venomous structures of the caterpillar Lonomia obliqua : identification of the proteins potentially involved in the coagulation disorder and hemorrhagic syndrome. Gene 2005, 355: I I-27.

38. Ong ST, Ho JZ, Ho B, Ding JL: Iron-withholding strategy in innate immunity. Immunobiology 2006, 2 I I:295-3 I4.

39. Ong DS, Wang L, Zhu Y, Ho B, Ding JL: The response of ferritin to LPS and acute phase of Pseudomonas infection. J Endotoxin Res 2005, II:267-280

40. Pham CG, Bubici C, Zazzeroni F, Papa S, Jones J, Alvarez K, Jayawardena S, De Smaele E, Cong R, Beaumont C, Torti FM, Torti SV, Franzoso G: Ferritin heavy chain upregulation by NF-kappaB inhibits TNFalpha-induced apoptosis by suppressing reactive oxygen species. Cell 2004, I I 9:529-542.

4I. Srivastava A, Casey H, Johnson N, Levy O, Malley R: Recombinant Bactericidal/permeability-increasing protein (rBPI2I) protects against pneumococcal disease. Infect Immun 2007, 75:342-349.

42. Eckert M, Wittmann I, Rollinghoff M, Gessner A, Schnare M: Endotoxin-induced expression of murine bactericidal permeability $/$ increasing protein is mediated exclusively by toll/IL-I receptor domain-containing adaptor inducing IFN-beta-dependent pathways. J Immunol 2006, 176:522-528.

43. Bingle $C D$, Craven $C$ ): Meet the relatives: a family of BPI- and LBP-related proteins. Trends Immunol 2004, 25:53-55.

44. Bulet P, Stocklin R, Menin L: Anti-microbial peptides: from invertebrates to vertebrates. Immunol Rev 2004, 198:169-184.

45. PEPD: Platynereis Expression Pattern Database [http:// ani.embl.de:8080/pepd/]

46. Ausubel FM, Brent R, Kingston RE, Moore DD, Seidman JG, Smith JA Struhl K: Current Protocols in Molecular Biology John Wiley and Sons, New York; 1987.

47. Basic Local Alignment Search T [http://www.ncbi.nlm.nih.gov/ BLAST/]

48. InterProScan Sequence Search [http://www.ebi.ac.uk/InterProS $\mathrm{can} /]$

49. Corpet F: Multiple sequence alignment with hierarchical clustering. Nucl Acids Res 1988, 16:10881-10890.

50. Multiple sequence alignment by Florence Corpet [http://bio info.genopole-toulouse.prd.fr/multalin/multalin.htm

5I. Ronquist F, Huelsenbeck JP: MrBayes 3, Bayesian phylogenetic inference under mixed models. Bioinformatics 2003, 19:1572-1574.

52. Jones DT, Taylor WR, Thornton JM: The rapid generation of mutation data matrices from protein sequences. Comput Appl BiosC 1992, 8:275-282.

53. Henikoff S, Henikoff JG: Amino acid substitution matrices from protein blocks. Proc Natl Acad Sci USA 1992, 89:10915-10919.

54. Page RDM: TREEVIEW: An application to display phylogenetic trees on personal computers. Comput Appl Biosci 1996, I 2:357-358

55. Huelsenbeck J, Rannala B: Frequentist properties of Bayesian posterior probabilities of phylogenetic trees under simple and complex substitution models. Syst Biol 2004, 53:904-913. 